\title{
Estudio comparativo in vitro de microfiltración corono-apical de Enterococcus faecalis luego de la obturación termoplastificada con vástago de gutapercha y con vástago de plástico en premolares uniradiculares
}

\section{Comparative in vitro study of corono-apical microfiltration of Enterococcus Faecalis after thermoplasticized gutta-percha stem and plastic stem filling in uniradicular premolars}

Recibido: 2018/01/20. Aceptado: 2018/02/25. Publicado: 2018/03/15

\section{Andrea Morales Huachi ${ }^{1}$ Johanna Monar Coloma ${ }^{2}$ Ana Cristina Chávez ${ }^{3}$}

1 Universidad San Francisco de Quito, Colegio de Ciencias de la Salud, Escuela de Odontología, Clínica Odontológica, Campus Cumbayá, oficina CO 106, casilla postal 17-1200-841. Quito-Ecuador.

Correo electrónico: andrelm_mb@hotmail.com

2 Universidad San Francisco de Quito, Colegio de Ciencias de la Salud, Escuela de Odontología, Clínica Odontológica, Campus Cumbayá, oficina CO 106, casilla postal 17-1200-841. Quito-Ecuador.

Correo electrónico: jmonar@usfq.edu.ec

3 Universidad San Francisco de Quito, Colegio de Ciencias Biológicas y Ambientales, Instituto de Microbiología, Campus Cumbayá, oficina EE 106, casilla postal 17-1200-841. Quito-Ecuador.

Correo electrónico: achavez@usfq.edu.ec 


\section{Resumen}

Este es un estudio experimental in vitro que comparó la microfiltración corono apical entre dos tipos de vástagos. Se ejecutó en 26 raíces dentarias humanas unirradiculares extraídas y divididas en 4 grupos: Guttacore: con vástago de gutapercha, Guttamaster: con vástago plástico, Control positivo: Sin ningún tipo de obturación y Control negativo: con vástago de gutapercha, cemento sellador y la superficie cervical sellada con ionómero de vidrio. Las raíces fueron ensambladas en tubos Falcón y selladas con masilla epóxica. En el tubo Falcón se colocó infusión cerebro-corazón donde se inoculó E. faecalis y luego fue introducido en tubos de ensayo de vidrio con reactivo de identificación de $E$. faecalis en contacto con el ápice de la raíz. Se mantuvo en observación durante 3 semanas hasta detectar un cambio en la coloración del reactivo. El análisis estadístico de Mann Whitney determinó que no existe diferencia estadísticamente significativa entre ninguno de los vástagos.

Palabras claves: vástago de gutapercha, vástago plástico, obturación, microfiltración, Enterococcus faecalis

\section{Abstract}

This experimental in vitro study compared apical coronal microleakage between two types of stems. It was performed on 26 unradicular human tooth roots extracted and divided into 4 groups: Guttacore: with gutta-percha stem, Guttamaster: with plastic stem, Positive control: Without any type of obturation and Negative control, with gutta-percha stem, sealing cement and the cervical surface sealed with glass ionomer. The roots were assembled into Falcon tubes and sealed with epoxy putty. Brain-heart infusion was placed in the Falcon tube where $E$. faecalis was inoculated and then introduced into glass test tubes with $E$. faecalis identification reagent in contact with the apex of the root. It was kept under observation for 3 weeks until a change in reagent staining was detected. Mann Whitney's statistical analysis determined that there is no statistically significant difference between any of the offspring.

Keywords: gutta-percha stem, plastic stem, obturation, microfiltration, Enterococcus faecalis 


\section{Introducción}

El propósito de la obturación es aislar al conducto ya limpio, conformado y preparado, proporcionando una compactación adecuada que no permita la filtración de microorganismos patógenos del entorno bucal hacia el sistema de conductos. Estas técnicas son utilizadas para realizar un sellado tridimensional del conducto radicular que ha sido tratado endodóncicamente 1-4.

La filtración corono apical ha sido estudiada desde hace mucho tiempo y se ha empleado un sin número de metodologías tales como: tinta de la India, radioisótopos, azul de metileno, colorantes, productos metabólicos de bacterias, entre otras. Mismas que nos permiten determinar si la compactación final de la obturación fue ideal o no ${ }^{2}$.

Una obturación inadecuada proporciona nutrientes a los microorganismos patógenos ya sea por vía coronal, periapical o por medio de conductos accesorios. Por lo que se puede generar una proliferación bacteriana que puede afectar el tratamiento y conducirlo al fracaso ${ }^{\text {1-5. }}$.

Una de las variantes dentro de la técnica de obturación vertical es el uso de distintos tipos de vástagos recubiertos de gutapercha. El primero desarrollado por Dentsply Tulsa Dental, que consta de un vástago metálico; posteriormente se empleó un vástago de plástico (Guttamaster) con la finalidad de facilitar la transportación de gutapercha en el interior del conducto radicular. Y en la actualidad se desarrolló un nuevo material en el cual se utiliza un vástago solamente de gutapercha (Guttacore) ${ }^{3}$.

El objetivo de la investigación fue determinar qué tipo de vástago ofrece una mayor resistencia a la microfiltración bacteriana entre el vástago de gutapercha (Guttacore) y el vástago plástico (Guttamaster) con la finalidad de determinar que material proporciona una compactación hermética del conducto radicular frente al microrganismo E. faecalis.

\section{Metodología}

El estudio es de tipo experimental in vitro comparativo descriptivo, la muestra constó de 26 premolares humanos unirradiculares extraídos por indicación ortodóncica en el periodo de noviembre a enero 2016.

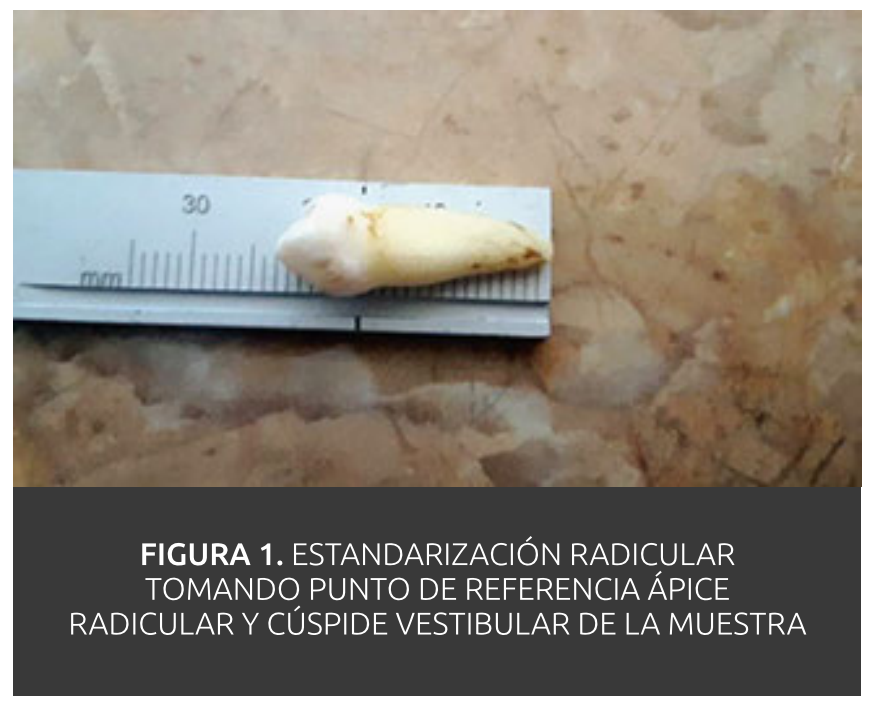

Se usó premolares unirradiculares superiores e inferiores extraídos de humanos sin procesos patológicos que involucren la superficie radicular, sin tratamiento de conducto previo, con grado de curvatura de Schneider máximo de 20 grados y que radiográficamente se observe el conducto permeable y ápices maduros.

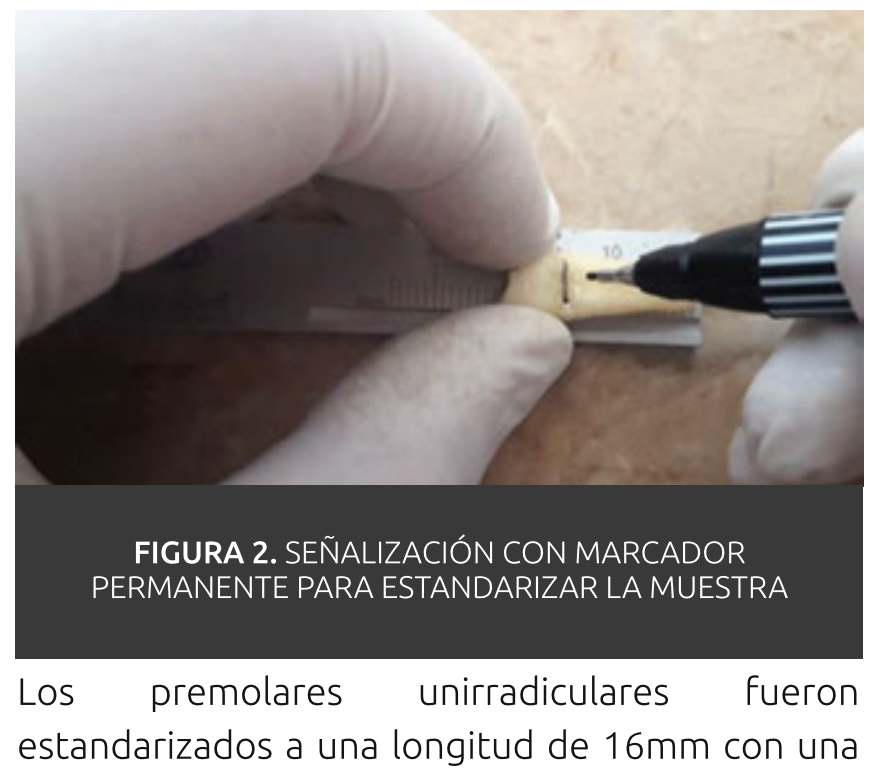


regla milimetrada, tomando como punto de referencia el ápice radicular y la cúspide vestibular.

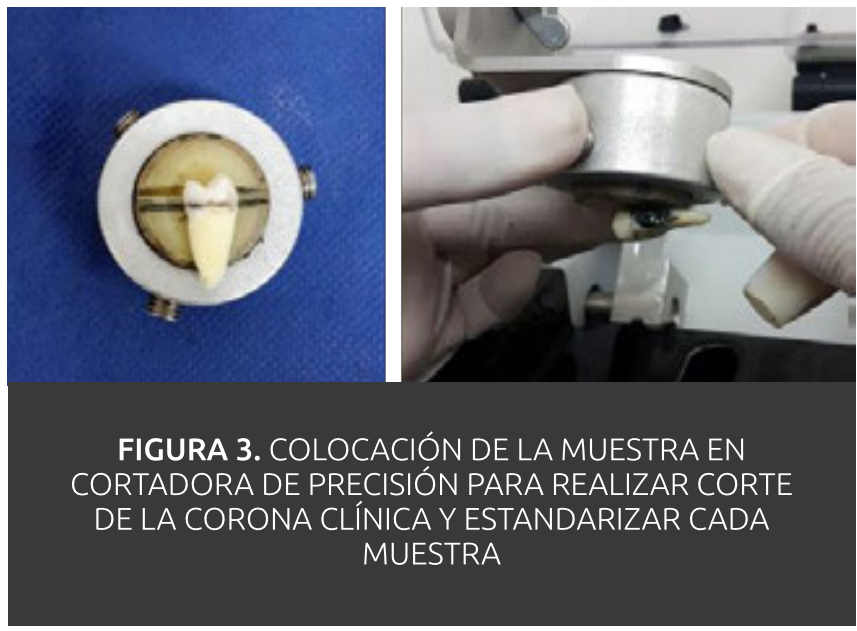

Una vez determinada la medida se señaló con un marcador permanente, para realizar el corte de la corona clínica de cada una de las muestras con la cortadora de precisión.

Las muestras fueron lavadas con agua destilada para remover cualquier tipo de suciedad. Posteriormente la muestra fue dividida de manera aleatoria en dos grupos experimentales.

Los grupos de estudio fueron designados de la siguiente manera:

- Grupo Control Positivo: Sin obturación, sin uso de vástago de gutapercha ni cemento sellador (3 muestras) Sistema de instrumentación RECIPROC.

- Grupo Control Negativo: Uso de vástago de obturación, cemento sellador y la superficie cervical de la raíz sellada con ionómero de vidrio (3 muestras) Sistema de instrumentación RECIPROC.

- Grupo GUTTACORE: Gutapercha Termoplastificada más Topseal. (10 muestras) Sistema de instrumentación RECIPROC.
- Grupo GUTTAMASTER: Gutapercha Termoplastificada más Topseal. (10 muestras). Sistema de instrumentación Mtwo.

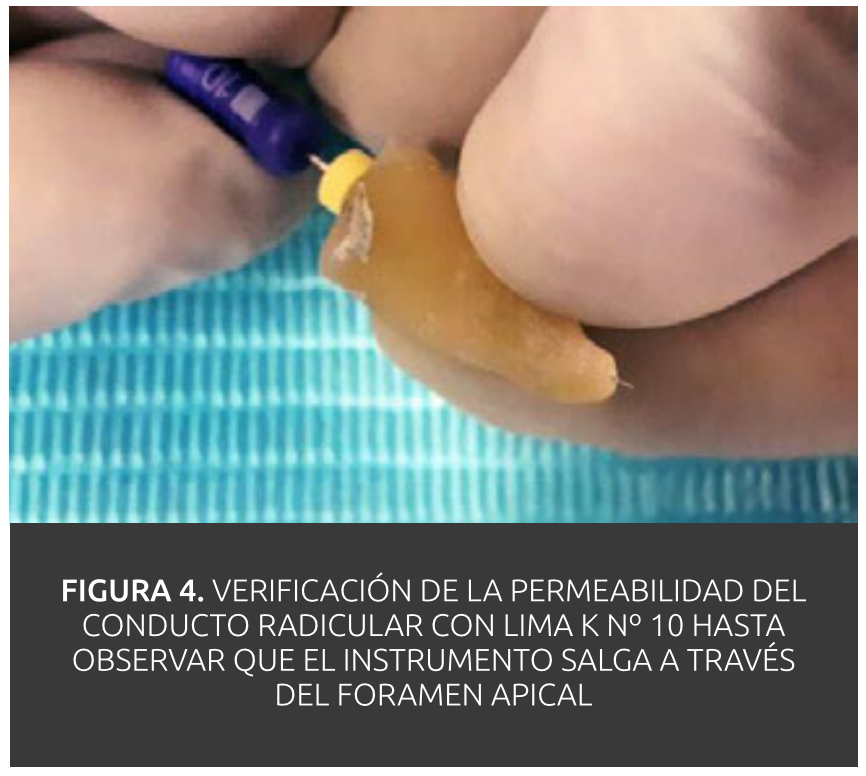

Luego se permeabilizaron los conductos radiculares con una Lima $\mathrm{K} \mathrm{N}^{\circ} 10$ a 16 mm hasta observar que el instrumento manual salga a través del foramen apical y posteriormente se irrigó con $1 \mathrm{~mL}$. de hipoclorito de sodio al 5.25\%.

Se determinó la longitud de trabajo con una lima $\mathrm{K} \mathrm{N}^{\circ}$ 15, disminuyendo $0.5 \mathrm{~mm}$ de la longitud estandarizada.

Se instrumentaron los conductos radiculares hasta una lima flexofile $N^{\circ} 20$ a la longitud establecida, para ensanchar el conducto radicular.

Se realizó la preparación biomecánica de los conductos radiculares, con el sistema de instrumentación de lima única RECIPROC, el grupo GUTTACORE mientras que el grupo GUTTAMASTER fue preparado con el sistema de instrumentación Mtwo.

Una vez finalizado el proceso de instrumentación se realizó el protocolo de irrigación del sistema de conductos radiculares con: $5 \mathrm{~mL}$. de hipoclorito de sodio al 5.25\% (Activación ultrasónica); después $5 \mathrm{~mL}$. de suero fisiológico y 
finalmente $5 \mathrm{~mL}$. de EDTA al $17 \%$ durante 3 minutos. Finalmente $5 \mathrm{~mL}$. de hipoclorito de sodio como irrigante final.

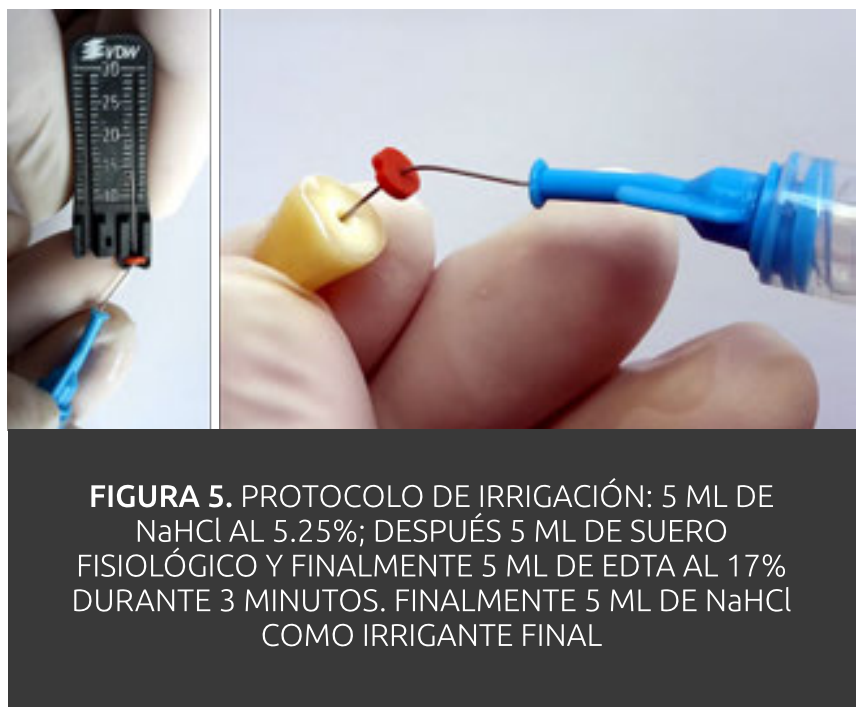

Todos los dientes fueron esterilizados en autoclave por 40 minutos a $121 \pm 2$ grados Celsius.

Luego se realizó la obturación de las muestras en el interior de la cámara de flujo laminar y se utilizó el horno Guttafusion de la marca VDW, el cual permite calentar los obturadores durante 30 segundos. El vástago se retira del horno y se inserta suavemente en el conducto al que previamente se le ha aplicado una fina capa de sellador previamente calibrado.

Las muestras fueron almacenadas en un frasco de orina estéril hasta la confección del ensamblaje de la raíz con los tubos de vidrio.

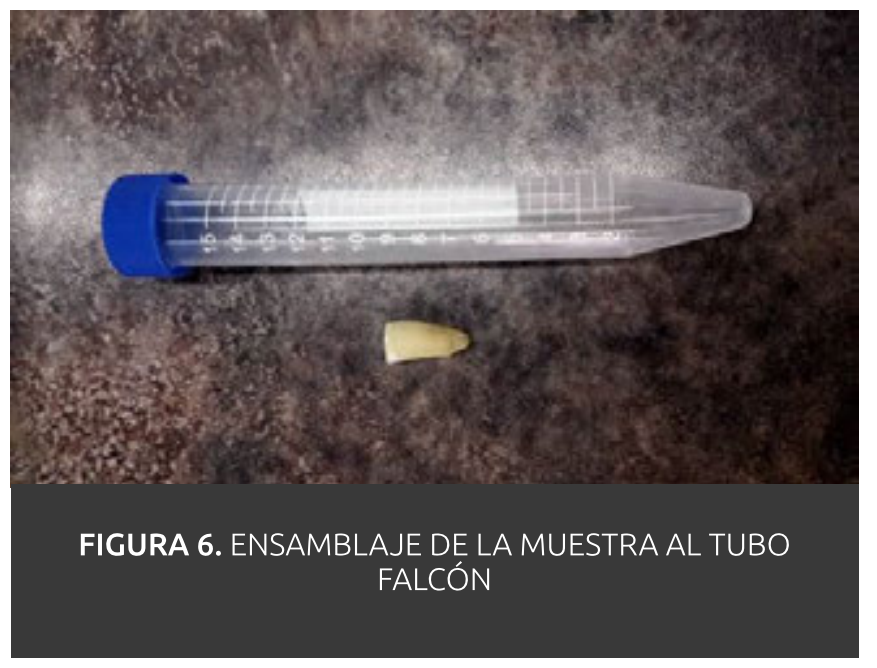

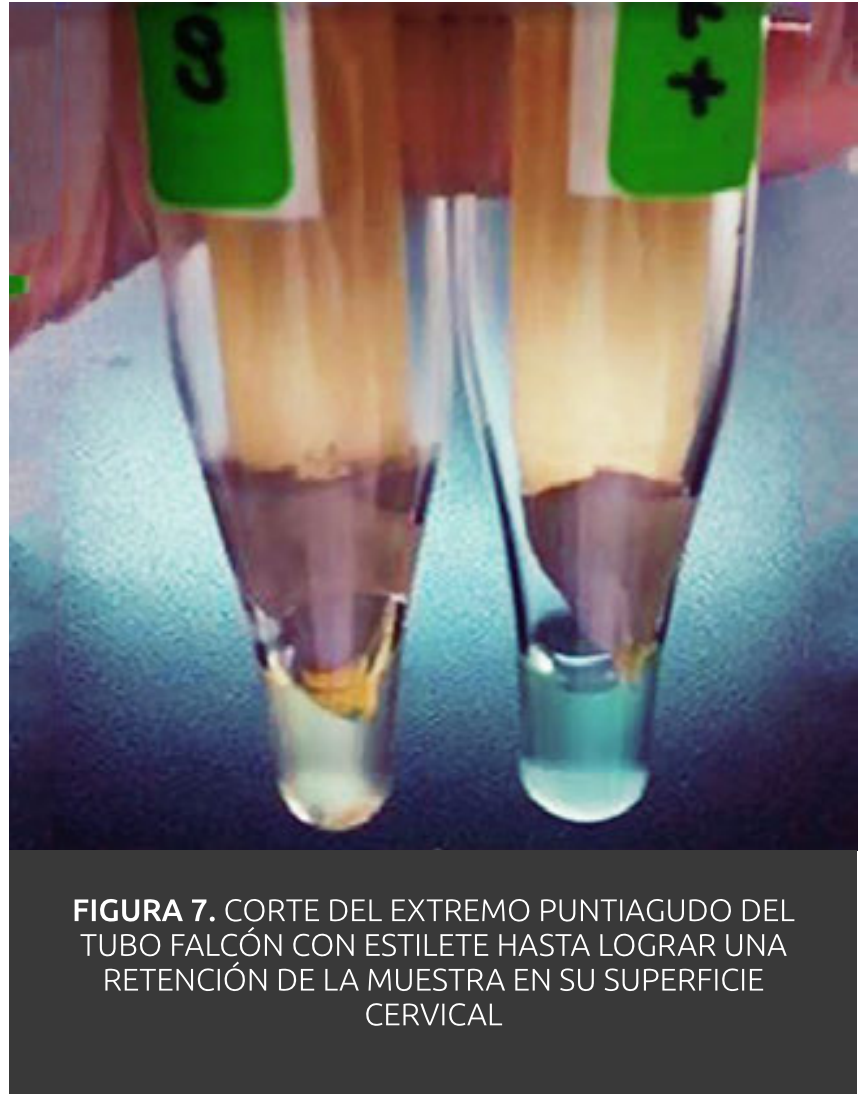

Posteriormente se procedió a realizar el ensamblaje de la experimentación, se procedió a cortar el extremo puntiagudo del tubo Falcón de $15 \mathrm{~mL}$ con la ayuda de un estilete, hasta que la raíz pudiera ingresar dejando $10 \mathrm{~mm}$. de la superficie radicular por fuera del tubo Falcón.

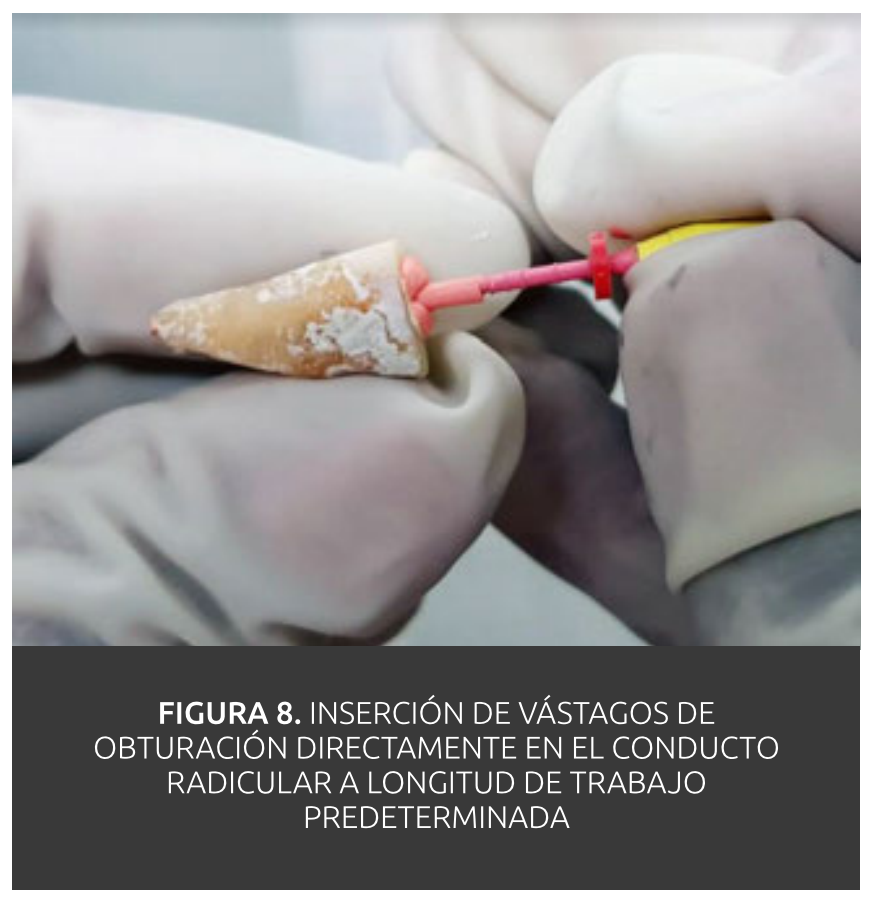


Posteriormente se adaptó la raíz al tubo Falcón calentando los extremos del tubo y fue enrollado en papel aluminio para enviarlo a la autoclave.

Cabe recalcar que las muestras fueron obturadas luego de ser enviadas a la autoclave, en el interior de la cámara de flujo laminar para mantener la asepsia de las mismas.

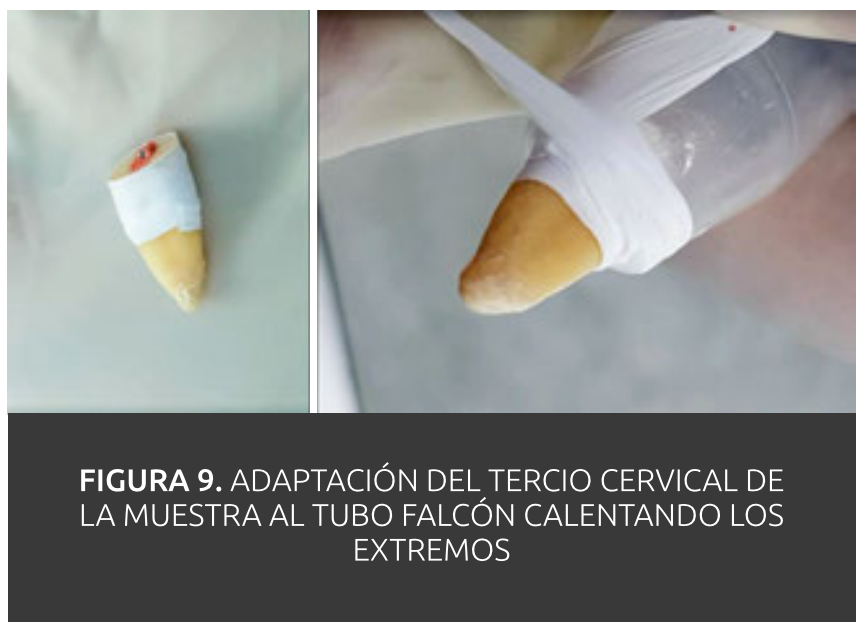

Una vez obturadas las muestras se colocó teflón en la superficie cervical de la raíz y fueron nuevamente introducidas en el tubo Falcón. Se colocó nuevamente teflón en la unión del tubo con la raíz para minimizar cualquier tipo de interfase entre la raíz y el tubo Falcón.

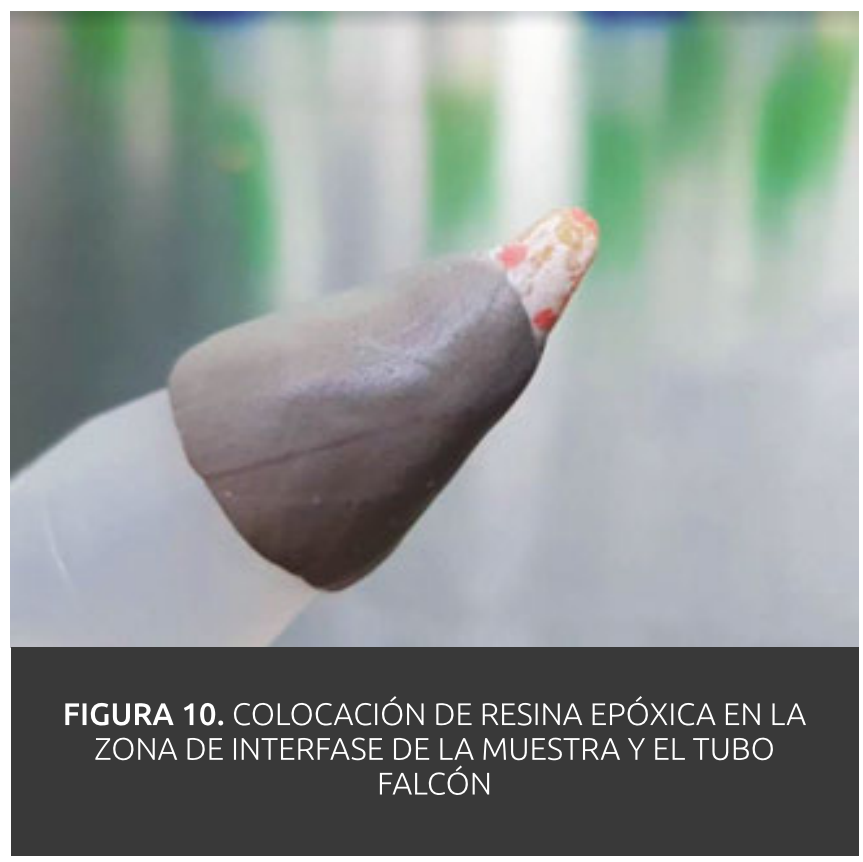

Finalmente se preparó la resina epóxica de acuerdo a las instrucciones del fabricante y se colocó alrededor de la raíz y el tubo. Luego fueron colocados en bandejas metálicas estériles y se dejó secar un día.

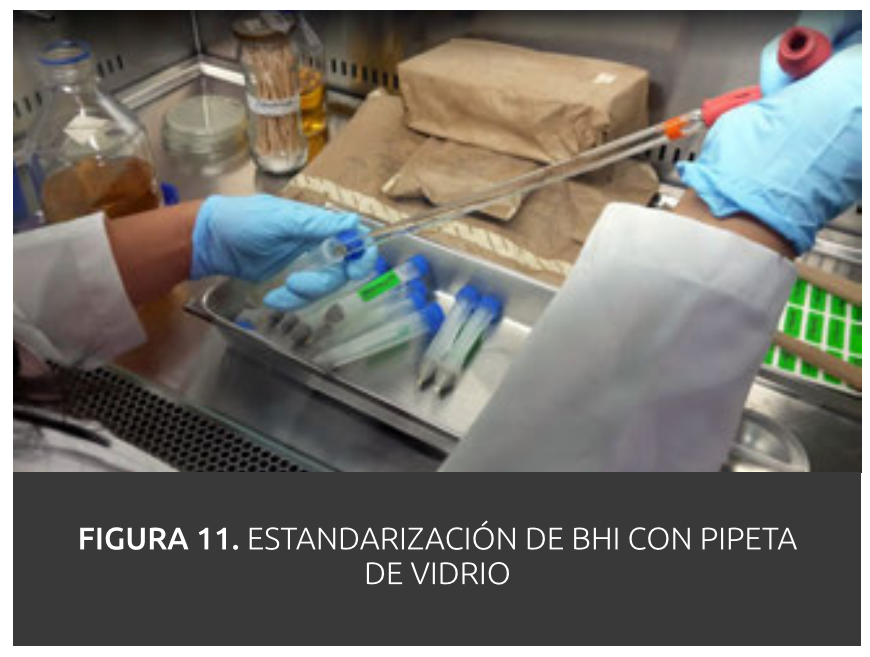

Con una micropipeta se colocó en un tubo de ensayo $10 \mathrm{~mL}$ de caldo nutritivo infusión cerebro corazón cuyas siglas en ingles son $\mathrm{BHI}$ de la marca Becton Dickinson. Posteriormente con un hisopo estéril se tomó un arrastre de colonias de Enterococcus faecalis ATCC 29212, mientras que los tubos de ensayo de vidrio con punta alargada fueron esterilizados.

Se procedió a colocar $10 \mathrm{~mL}$ de $\mathrm{BHI}$ inoculado con Enterococcus faecalis en el interior del tubo Falcón con la ayuda de una pipeta de vidrio y se selló con su respectiva tapa.

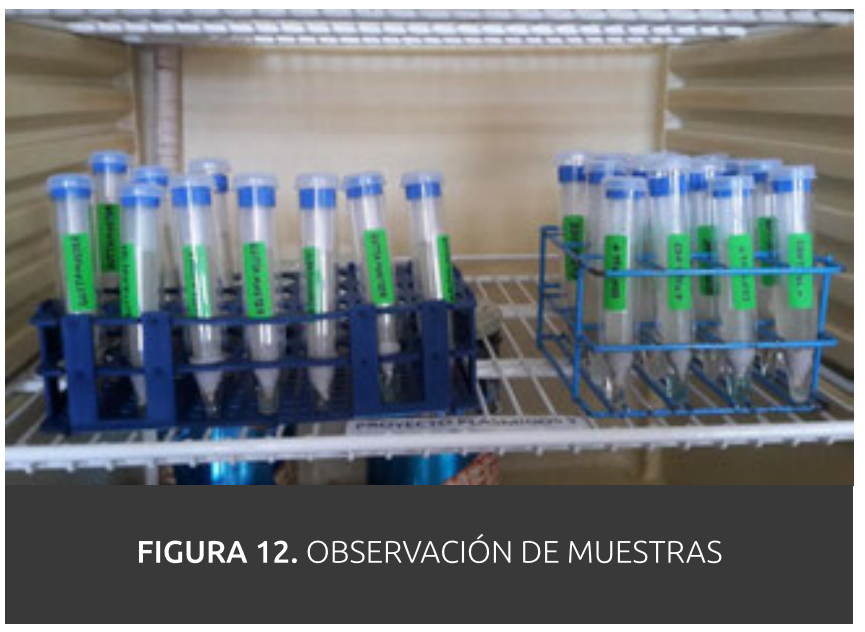

En el tubo de ensayo de vidrio se colocó el Chromocult con una pipeta plástica que fue caEn 
el tubo de ensayo se colocó el caldo de Chromocult $\circledast$ Enterococci Broth de la marca MERCK, éste caldo permite detectar la presencia de la enzima Beta-D-Glucosidasa propia del Enterococcus, la cual si ésta presente cambia el color del caldo de Chromocult $®$ de amarillo a azul verdoso. Posteriormente se introdujo el tubo Falcón hasta que la punta de la raíz entró en contacto con el caldo de Chromocult@, se selló el tubo de ensayo con una contratapa.

Todas las muestras rotuladas fueron colocadas en una gradilla en el interior de la incubadora a 35.9 grados Celsius. Los tubos fueron observados a diario durante un período de 3 semanas. El caldo de $\mathrm{BHI}$ de cada tubo se cambió cada tres días. Se anotó a los cuantos días se produjo la filtración bacteriana en cada una de las muestras.

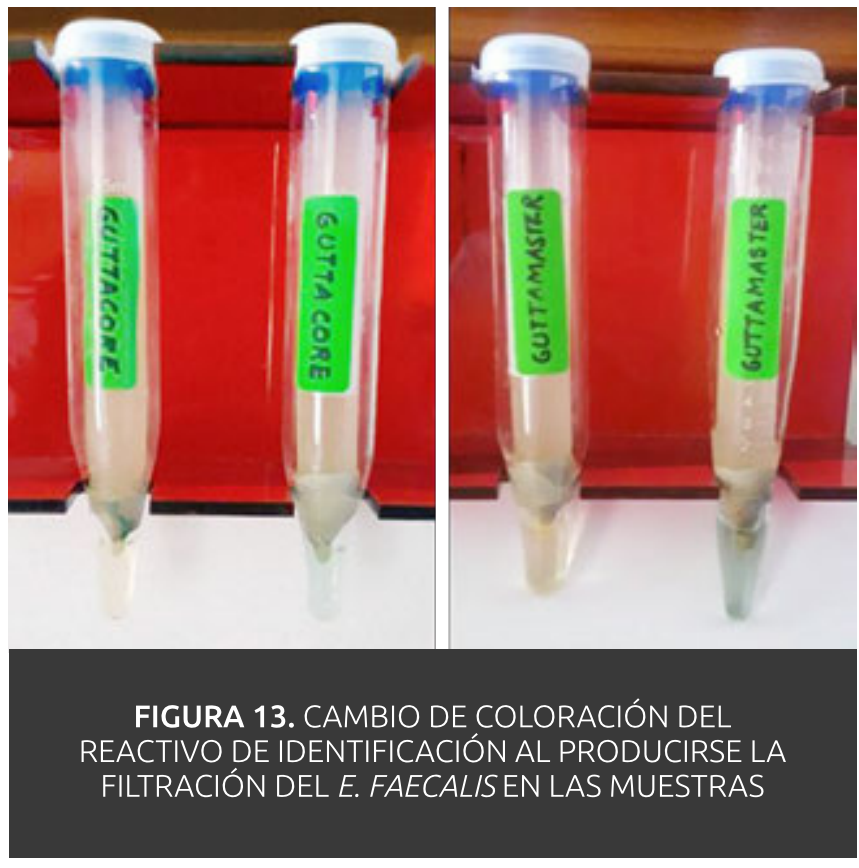

Resultados

\section{Análisis descriptivo}

Los datos se obtuvieron de la observación diaria realizada a las muestras, identificando el día en el que hubo cambio de color del reactivo de identificación (Chromocult@) producto de la filtración bacteriana ( $E$. faecalis) que atravesó el material de obturación a lo largo del conducto radicular en los distintos grupos.
Los grupos de obturación presentaron datos de importancia como la media y la desviación estándar a excepción del grupo de control negativo al no presentarse una filtración de las muestras estos datos se considerados como perdidos.

\begin{tabular}{|l|l|l|}
\hline MUESTRA & MEDIA & DESVIACIÓN ESTÁNDAR \\
\hline Control Positivo & 1,67 & 1,155 \\
\hline Vástago de Gutapercha & 13,60 & 6,494 \\
\hline Vástago Plástico & 11,90 & 7,978 \\
\hline
\end{tabular}

TABLA 1. ANÁLISIS DESCRIPTIVO DE MEDIA Y DESVIACIÓN ESTÁNDAR DE LAS MUESTRAS

Se realizó la prueba Shapiro-Wilk para contrastar la hipótesis de normalidad. Las hipótesis en la prueba de normalidad son:

Ho: Las muestras presentan distribución normal $(p>0,05)$

Ha: Las muestras no presentan distribución normal $(p<0,05)$

Para aceptar la hipótesis nula el valor de significancia debe ser mayor a 0,05 caso contrario se acepta la hipótesis alterna.

En este estudio los valores de significancia son inferiores a 0,05 (95\% de confiabilidad), por tanto, se aceptó la $\mathrm{Ha}$, esto indica que las muestras no provienen de poblaciones con distribución normal. Entonces para la comparación de grupos se utilizó las pruebas no paramétricas: Prueba de comparaciones en pareja y Mann Whitney.

Para determinar entre qué grupos se presentó una diferencia estadísticamente significativa, se realizó la prueba de comparaciones por pareja.

Las hipótesis en la prueba de comparaciones por pareja son:

Ho: No hay diferencia estadísticamente significativa entre los grupos. ( $p>0,05)$ 


\begin{tabular}{|c|c|c|c|c|c|}
\hline & \multicolumn{5}{|c|}{ DESCRIPTIVOS } \\
\hline & $\begin{array}{l}\text { GRUPO DE } \\
\text { OBTURACIÓN }\end{array}$ & & & ESTADÍSTICO & $\begin{array}{l}\text { ERROR } \\
\text { ESTÁNDAR }\end{array}$ \\
\hline \multirow[t]{13}{*}{$\begin{array}{l}\text { DÍA DE } \\
\text { OBTURACIÓN }\end{array}$} & $\begin{array}{l}\text { VÁSTAGO DE } \\
\text { GUTAPERCHA }\end{array}$ & MEDIA & & 13,8 & 2,054 \\
\hline & & & LIMITE SUPERIOR & 9,35 & \\
\hline & & $\begin{array}{l}95 \% \text { DE } \\
\text { INTERVALO DE } \\
\text { CONFIANZA PARA } \\
\text { MEDIA }\end{array}$ & LIMITE INFERIOR & 18,45 & \\
\hline & & $\begin{array}{l}\text { MEDIA } \\
\text { RECORTADA AL } \\
5 \%\end{array}$ & & 13,83 & \\
\hline & & MEDIANA & & 13 & \\
\hline & & VARIANZA & & 42,178 & \\
\hline & & $\begin{array}{l}\text { DESVIACIÓN } \\
\text { ESTÁNDAR }\end{array}$ & & 6,494 & \\
\hline & & MÍNIMO & & 4 & \\
\hline & & MÁXIMO & & 23 & \\
\hline & & RANGO & & 19 & \\
\hline & & $\begin{array}{l}\text { RANGO } \\
\text { INTERCUARTIL }\end{array}$ & & 11 & \\
\hline & & ASIMETRÍA & & $-0,32$ & 0,687 \\
\hline & & CURTOSIS & & $-1,274$ & 1,334 \\
\hline
\end{tabular}

\section{TABLA 2. ANÁLISIS DESCRIPTIVO DE VÁSTAGO DE GUTAPERCHA}

\begin{tabular}{|c|c|c|c|c|c|}
\hline & \multicolumn{5}{|c|}{ DESCRIPTIVOS } \\
\hline & $\begin{array}{l}\text { GRUPO DE } \\
\text { OBTURACIÓN }\end{array}$ & & & ESTADÍSTICO & $\begin{array}{l}\text { ERROR } \\
\text { ESTÁNDAR }\end{array}$ \\
\hline \multirow[t]{13}{*}{$\begin{array}{l}\text { DÍA DE } \\
\text { OBTURACIÓN }\end{array}$} & $\begin{array}{l}\text { VÁSTAGO DE } \\
\text { PLÁSTICO }\end{array}$ & MEDIA & & 11,9 & 2,523 \\
\hline & & & LIMITE SUPERIOR & 6,19 & \\
\hline & & $\begin{array}{l}95 \% \text { DE } \\
\text { INTERVALO DE } \\
\text { CONFIANZA PARA } \\
\text { MEDIA }\end{array}$ & LIMITE INFERIOR & 17,61 & \\
\hline & & $\begin{array}{l}\text { MEDIA } \\
\text { RECORTADA AL } \\
5 \%\end{array}$ & & 11,94 & \\
\hline & & MEDIANA & & 12,5 & \\
\hline & & VARIANZA & & 63,656 & \\
\hline & & $\begin{array}{l}\text { DESVIACIÓN } \\
\text { ESTÁNDAR }\end{array}$ & & 7,978 & \\
\hline & & MÍNIMO & & 1 & \\
\hline & & MÁXIMO & & 22 & \\
\hline & & RANGO & & 21 & \\
\hline & & $\begin{array}{l}\text { RANGO } \\
\text { INTERCUARTIL }\end{array}$ & & 16 & \\
\hline & & ASIMETRÍA & & $-0,55$ & 0,687 \\
\hline & & CURTOSIS & & $-1,63$ & 1,334 \\
\hline
\end{tabular}




\begin{tabular}{|c|c|c|c|c|c|}
\hline & \multicolumn{5}{|c|}{ DESCRIPTIVOS } \\
\hline & $\begin{array}{l}\text { GRUPO DE } \\
\text { OBTURACIÓN }\end{array}$ & & & ESTADÍsTICO & $\begin{array}{l}\text { ERROR } \\
\text { ESTÁNDAR }\end{array}$ \\
\hline \multirow[t]{13}{*}{$\begin{array}{l}\text { DÍA DE } \\
\text { OBTURACIÓN }\end{array}$} & $\begin{array}{l}\text { CONTROL } \\
\text { POSITIVO }\end{array}$ & MEDIA & & 1,67 & 0,667 \\
\hline & & & LIMITE SUPERIOR & $-1,2$ & \\
\hline & & $\begin{array}{l}95 \% \text { DE } \\
\text { INTERVALO DE } \\
\text { CONFIANZA PARA } \\
\text { MEDIA }\end{array}$ & LIMITE INFERIOR & 4,54 & \\
\hline & & $\begin{array}{l}\text { MEDIA } \\
\text { RECORTADA AL } \\
5 \%\end{array}$ & & & \\
\hline & & MEDIANA & & 1 & \\
\hline & & VARIANZA & & 1,333 & \\
\hline & & $\begin{array}{l}\text { DESVIACIÓN } \\
\text { ESTÁNDAR }\end{array}$ & & 1,155 & \\
\hline & & MÍNIMO & & 1 & \\
\hline & & MÁXIMO & & 3 & \\
\hline & & RANGO & & 2 & \\
\hline & & $\begin{array}{l}\text { RANGO } \\
\text { INTERCUARTIL }\end{array}$ & & & \\
\hline & & ASIMETRÍA & & 1,732 & 1,225 \\
\hline & & CURTOSIS & & & \\
\hline
\end{tabular}

\section{TABLA 4. ANÁLISIS DESCRIPTIVO CONTROL POSITIVO}

Ha: Si hay diferencia estadísticamente significativa entre los grupos. $(p<0,05)$

De acuerdo a esta prueba existe diferencia estadísticamente significativa entre el control positivo y el grupo de vástago plástico $(p=0,033)$. Así como en el control positivo y vástago de gutapercha $(p=0,012)$. Pero no presentó una diferencia estadísticamente significativa entre ambos tipos de vástagos $(p=0,574)$.

Рara encontrar similitudes o diferencias entre los tiempos de contaminación de las muestras de los diferentes grupos (T1-T23) se realizó la prueba de Mann Whitney:

Las hipótesis en la prueba no paramétrica de Mann Whitney son:

Ho: No hay diferencia estadísticamente significativa entre las muestras de vástago de gutapercha y vástago plástico. $(p>0,05)$
Ha: Si hay diferencia estadísticamente significativa entre las muestras de vástago de gutapercha y vástago plástico. $(p<0,05)$

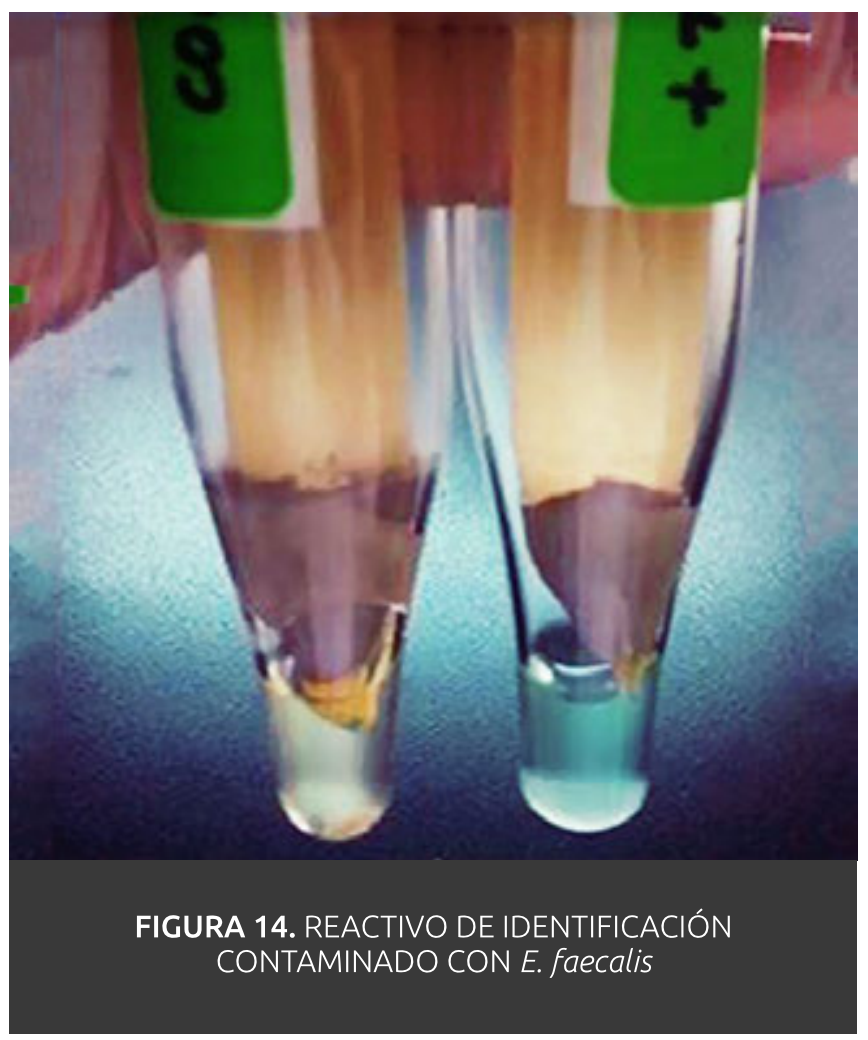




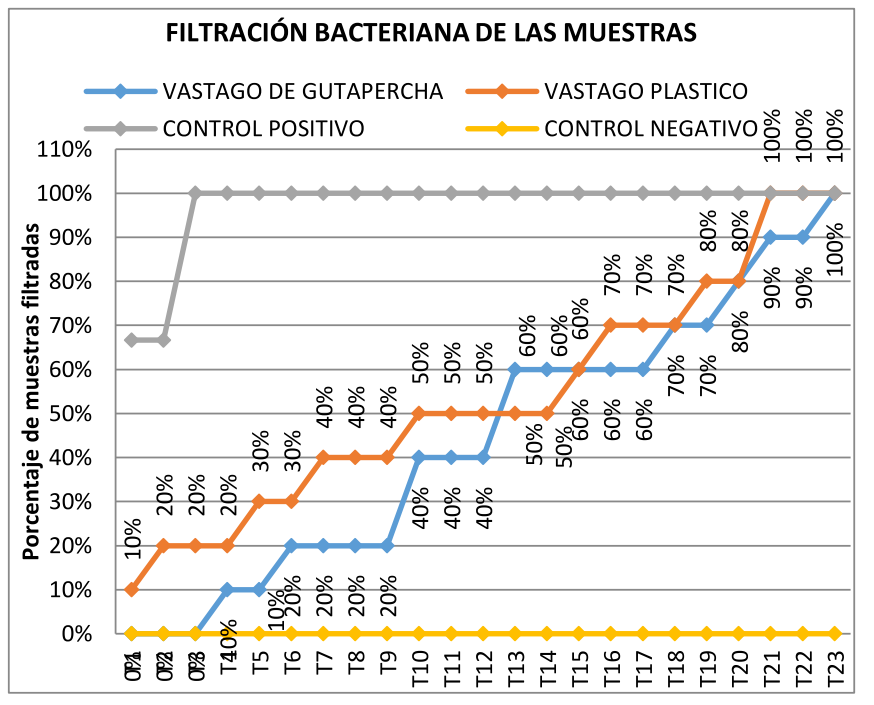

TABLA 5. FILTRACIÓN DIARIA DE LAS MUESTRAS CONTAMINADAS CON E. faecalis

Comparaciones por parejas de GRUPO DE OBTURACION

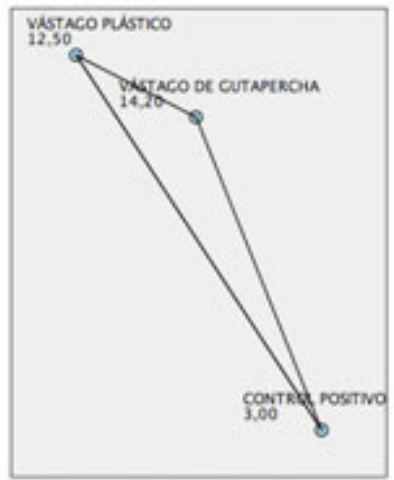

Cada nodo muestra el range promedio de muestra de Crupo oE CaruRACioN.

\begin{tabular}{|c|c|c|c|c|c|}
\hline Nwestra 1-Muesura 2 & $\begin{array}{l}\text { Estadistico } \\
\text { de prueba }\end{array}$ & $\begin{array}{c}\text { Estándar } \\
\text { Error }\end{array}$ & $\begin{array}{l}\text { Desy. Estadistico } \\
\text { de pruetba }\end{array}$ & Sig. & Sig. ajust. \\
\hline $\begin{array}{l}\text { CONTRROL POSITIVO-VÁSTACO } \\
\text { PLASTICO }\end{array}$ & 9,500 & 4,454 & 2,133 & .033 & .196 \\
\hline $\begin{array}{l}\text { CONTROL POSITIVO-VASTACO } \\
\text { DE CUTARECAM }\end{array}$ & 11.200 & 4,454 & 2.515 & .012 & .07 \\
\hline $\begin{array}{l}\text { VÁSTACO PLASTINO- } \\
\text { VASTACO DE CUTAPECOHA }\end{array}$ & 1,700 & 3,026 & .562 & .574 & 1,000 \\
\hline
\end{tabular}

Cada fila orveba la hipótesis nula hipbresis nula de que las distribuciones de la muestra 1 y la muestra 2 Se mustertran las significaciones asintóticas (onvebas Bilaterales). El nivel de significancia es .05.

FIGURA 14. REACTIVO DE IDENTIFICACIÓN CONTAMINADO CON E. FAECALIS

\begin{tabular}{|l|l|}
\hline \multicolumn{2}{|l|}{ ESTADIISTICO DE PRUEBA } \\
\hline & DÍA DE FILTRACIÓN \\
\hline U DE MANN-WHITNEY & 43 \\
\hline W DE WILCOXON & 98 \\
\hline Z & $-0,53$ \\
\hline SIG. ASINTÓNICA & 0,596 \\
\hline SIGNIFICACIÓN EXACTA & 0,631 \\
\hline
\end{tabular}

TABLA 7. PRUEBA ESTADÍSTICA DE MANN WHITNEY COMPARANDO TIEMPO DE FILTRACIÓN ENTRE LAS MUESTRAS DE VÁSTAGO

El valor de significancia en la prueba de Mann Whitney es de 0.596 es decir que $(p>0.05)$ por lo que se acepta la hipótesis nula. Se determina que no existe diferencia estadísticamente significativa entre los dos tipos de vástagos.

\section{Discusión}

La presente investigación evaluó el grado de micro filtración bacteriana corono-apical en dientes unirradiculares obturados con vástagos de gutapercha y vástago plástico usando cemento TopSeal.

El motivo por el que se realizó dicha experimentación con cepas bacteriana de Enterococcus faecalis fue porque se lo considera el principal microrganismo bacteriano encontrado en infecciones endodóncicas persistentes. Esto está relacionado con su patogenicidad ya que es un microorganismo anaerobio facultativo y Gram positivo, que se aísla con mayor frecuencia en casos de fracaso endodóncico $\mathbf{6 , 7 , 8}$.

Posee la capacidad de sobrevivir y crecer en conductos radiculares con nutrientes limitados. Otro factor de patogenicidad es su adhesión a la superficie dentinal, debido a que la dentina contiene colágeno y otras proteínas que permiten que se produzca una adhesión 
bacteriana resistente que permite al microorganismo colonizar nuevamente el conducto radicular $9, \mathbf{1 0 , 1 1 , 1 9}$.

Otro factor asociado al fracaso del tratamiento endodóncico es la inadecuada adaptación protésica o restauradora, que permite el ingreso de microorganismos de la cavidad oral al sistema de conductos 12,20 .

En el presente estudio se buscó determinar en qué intervalo de tiempo se produjo la microfiltración del $E$. faecalis a través de los vástagos de obturación desde la porción cervical de la raíz hasta que alcance la porción apical de la misma.

La experimentación fue monitoreada durante 3 semanas hasta que todas las muestras presenten una contaminación bacteriana con la cepa anteriormente mencionada.

Se debe tomar en cuenta que los vástagos de obturación de gutapercha al ser nuevos en el mercado no presentan una línea de investigación amplia con lo referente a la microfiltración corono-apical. Por lo que se realizarán comparaciones con estudios lo más cercano al tema. Cabe recalcar que no hay un estudio que presente una comparación de microfiltración corono-apical con diferentes vástagos de obturación.

En este estudio experimental In vitro, se buscó comprobar qué tipo de vástago de obturación ofrecía una mayor resistencia frente a la microfiltración bacteriana. De acuerdo a los resultados obtenidos no se encontró una diferencia estadísticamente significativa a pesar de que la filtración de las muestras de vástago plástico se produjo en un intervalo de tiempo más acelerado que las muestras de vástago de gutapercha.

En el estudio experimental In vitro, Inan y col. realizó una comparación del grado de filtración entre las técnicas System $B$, Thermafill y compactación lateral en frío. Se utilizaron 20 muestras por grupo, una vez que fueron obturadas, las sumergieron en tinta china durante 7 días para posteriormente diafanizarlas para su evaluación en MEB. No se obtuvieron diferencias estadísticamente significativas entre ninguno de los grupos. Estos resultados coinciden con dicha experimentación ${ }^{13}$.

Martínez y col. realizaron un estudio comparativo de microfiltración apical entre las técnicas de obturación: Calamus, Guttacore y Guttafusion. En la cual se utilizaron 78 conductos mesiales de 39 primeros molares mandibulares, que fueron divididos en 3 grupos de 26 muestras cada uno. Luego fueron sumergidos en tinta china $y$ diafanizados para observar filtración apical del tinte bajo microscopía. En este estudio no se encontraron diferencias estadísticamente significativas, ya que obtuvieron una filtración promedio de $0,79 \mathrm{~mm}$ a $1,42 \mathrm{~mm}$ en todas las técnicas de obturación empleadas ${ }^{14}$.

Hwang y col. evaluó la penetraciónbacterianas y sellado tridimensional en sesenta premolares unirradiculares los cuales se dividieron en 4 grupos experimentales para ser obturados. El grupo CW (Continuous Wave) obturado con la técnica de onda continúa. El grupo GC (Guttacore) obturado con vástago de gutapercha. El grupo GF (GuttaFlow) fue obturado usando gutapercha fluida. El grupo EM que utilizó endoseal, MTA y gutapercha fluida mediante vibración ultrasónica para su obturación. El cemento sellador AH-Plus fue utilizado en los tres primeros grupos. Posteriormente en la punta de la raíz de las muestras se incubó con $E$. faecalis teñida con Diacetato de carboxifluoresceína (fluorescencia) durante 14 días. Se analizó la penetración bacteriana en la sección apical a 1, 2 , $3 \mathrm{~mm}$ mediante el de uso microscopia laser confocal. El grupo CW, GC y EM exhibieron la menor penetración bacteriana que el grupo GF. No hubo una diferencia estadísticamente significativa entre los tres grupos mencionados anteriormente. Es decir que en este estudio no se 
podría determinar una superioridad de ninguno de los materiales de obturación utilizados en dicha experimentación ${ }^{15}$.

Aragón y col. evaluó el grado de microfiltración de $E$. faecalis en 5 técnicas de obturación: Condensación lateral, condensación vertical, cono único, vástago de gutapercha Guttacore y condensación híbrida-mixta. Se usaron 50 premolares a los cuales se inoculó la cepa bacteriana nombrada anteriormente en la porción coronal. La microfiltración se determinó mediante el cambio de color de un medio de cultivo con rojo de fenol durante 12 semanas. Las muestras fueron observadas mediante microscopia electrónica de barrido. En este estudio se determinó que la condensación híbrida-mixta mostró ser la más eficiente ya que no presentó ninguna microfiltración en relación al resto de técnicas. Este es el único estudio que difiere con los resultados obtenidos en dicha experimentación. Pero la investigación compara obturación del vástago de gutapercha con técnicas que difieren entre ellas, por este motivo no es un estudio relevante ${ }^{16}$.

Roméas y col. evaluó el grado de microfiltración apical en 74 dientes unirradiculares extraídos, los mismos que fueron instrumentados con un tamaño apical 30. La muestra se dividió en tres grupos experimentales: 20 muestras fueron obturados con técnica de condensación lateral, 20 con compactación vertical termoplastificada y 20 dientes con el sistema Herofill obturación vástago de plástico. Los dientes se cubrieron con barniz de uñas hasta $2 \mathrm{~mm}$ del foramen apical y se sumergieron en una solución de colorante de azul de metileno durante 1 semana y luego se lavaron, se deshidrataron y se incrustaron en resina. Se realizaron micro cortes para revelar el límite apical de la preparación. Las secciones transversales fueron a 500, 1000 y 1500 micrómetros y se evaluaron las fugas apicales (penetración del colorante). El sistema Herofill mostró un menor porcentaje de filtración apical en relación a la técnica de compactación lateral.
Pero no mostró una diferencia estadísticamente significativa entre Herofill y la técnica vertical termoplastificada ${ }^{\mathbf{1 7}}$.

En 2016, Tuculina y col. hacen una comparación para determinar la calidad de la obturación entre la gutapercha termoplastificada de vástago plástico (Guttamaster) y el sistema de obturación vertical. Lo realizaron a través del método de transparencia que consistía en descalcificar las muestras una vez obturadas en ácido cítrico. Ambas muestras mostraron una obturación homogénea sin embargo la técnica de obturación vertical mostró superioridad al penetrar en los conductos laterales ${ }^{\mathbf{1 8}}$.

Finalmente se podría decir que la composición del vástago no es un factor de importancia o de relevancia cuando se produce una filtración bacteriana. Se lo considera como un medio de transporte de la gutapercha reblandecida para que ingrese más fácilmente al sistema de conductos radiculares. Por lo que el vástago de gutapercha como el vástago plástico ofrece un sellado tridimensional similar.

\section{Conclusiones}

Por la dificultad de conseguir el material de obturación (Guttacore y Guttamaster) en el Ecuador no se pudo hacer grupos de estudio con un mayor número de muestras, sin embargo, con las limitaciones del estudio se puede concluir:

- En el caso de las muestras de vástago de gutapercha (Guttacore) se tiene que al tiempo 1 (T1) no ha filtrado ninguno de los elementos, al tiempo 10 (T10) ha filtrado el $40 \%$ de los elementos y al Tiempo 23 (T23) han filtrado el $100 \%$ de los elementos.

- En el caso de las muestras de vástago de plástico (Guttamaster) se tiene que al tiempo 1 (T1) ha filtrado el $10 \%$ de los 
elementos, al tiempo 10 (T10) ha filtrado el $50 \%$ de los elementos y al Tiempo 20 (T20) han filtrado el $100 \%$ de los elementos.

- A pesar de que la filtración bacteriana de las muestras de vástago de plástico, se presentaron más aprisa que las muestras de gutapercha no hubo una diferencia estadísticamente significativa que permita diferir cuál de los dos vástagos presenta una mayor resistencia frente a la microfiltración bacteriana $(p>0,05)$.

- Se concluyó que el tipo de vástago no infiere directamente en la obturación de los conductos radiculares y que actúa como el medio de transporte de la gutapercha reblandecida.

\section{Referencia bibliográfica}

1. Sánchez P. Estudio comparativo in vitro de microfiltración corono-apical de Enterococcus Faecalis entre diferentes técnicas y materiales de obturación en dientes unirradiculares. Universidad San Francisco de Quito; Tesis de postgrado. 2011. 5-61.

2. Da Costa M. Penetration of a resin-based filling material into lateral root canals and quality of obturation by different techniques. Brazilian Oral Research. 2015;29(1):1-5.

3. Eitten R. The Effect of Canal preparation on Fill Length in Straight Root Canals Obturated with Guttacore; American Association of Endodontists; Journal of Endodontics. 2015;41(2):155-158.

4. Zhang Ch. Correlation between Enterococcus Faecalis and Persistent
Intraradicular Infection Compared with Primary Intraradicular Infection: A Systematic Review; Journal of Endodontics. 2015;41(8):1207-1213.

5. De Almeida et al. Effectiveness of EDTA and Modified Salt Solution to Detach and Kill Cells from Enterococcus faecalis Biofilm. JOE. 2016;42(2):320-323.

6. Pinheiro S. Evaluation of root canal microorganisms isolated from teeth with endodontic failure and their antimicrobial susceptibility. Oral Microbiology Immunology. 2003;18(2):100-103.

7. Palaniswamy S. Effectiveness of $\mathbf{N}$-acetyl cysteine, 2\% chlorhexidine, and their combination as intracanal medicaments on Enterococcus faecalis biofilm: Journal of Conservative Dentistry. 2016;19(1):17-20.

8. Penas P. Analysis of Genetic Lineages and Their Correlation with Virulence Genes in Enterococcus faecalis Clinical Isolates from Root Canal and Systemic Infections; Journal of Endodontics. 2013;39(7):858864.

9. De Almeida et al. Effectiveness of EDTA and Modified Salt Solution to Detach and Kill Cells from Enterococcus faecalis Biofilm. JOE. 2016;42(2):320-323.

10. Furuya M. Evaluación de la actividad antibacteriana en una mezcla de hidróxido de calcio y clorhexidina al $0.12 \%$ como irrigante pulpar. Revista Oral. 2006;7(23):355-359. 
11. Hubble S. Influence of Enterococcus Faecalis proteases and the collagenbinding protein, Ace, on adhesion to dentin. Oral Microbiology Immunology. 2003;18(2):121-126.

12. Molven. Editorial Board. Success and Failure in Endodontics: An Online Study Guide. Endodontic Study Guide. Journal of Endodontics. 2008;34(5):1-6.

13. Inan $U$. Leakage evaluation of three different root canal obturation techniques using electrochemical evaluation and dye penetration evaluation methods. Aust Endod Journal. 2007;33(1):18-22.

14. Martínez A. Estudio comparativo de filtración apical entre las técnicas de obturación lateral y vertical en endodoncia. Oral Revista. 2011;33(1):573576.

15. Hwang JH. Comparison of bacterial leakage resistance of various root canal filling materials and methods: Confocal laser-scanning microscope study. Department of Oral Microbiology of Pusan National University, Korea. 2015;37(6):422428.

16. Aragón S. Evaluación in vitro de la microfiltración de Enterococcus faecalis usando cinco técnicas de obturación. Univ Odontol. 2016;35(74):3-23.

17. Roméas A. In vitro evaluation of apical microleakage following canal filling with a coated carrier system compared with lateral and thermomechanical GuttaPercha condensation techniques. International Endodontics Journal. 2003;35(74):27-30.
18. Tuculina M. Comparative Study Regarding Two Obturation Methods With Thermoplasticized Gutta-Percha For The Root Canals. University of Dentistry and Pharmacy of Craiova. 2016;695(1):12-19.

19. Basrani M. Using Diazotization to Characterize the Effect of Heat or Sodium Hypochlorite on 2.0\% Chlorhexidine. JOE. 2009;35(9):1296-1299.

20. Lasala, A. Endodoncia. Editorial Panamericana. 2012;76-89. 